\title{
Analysis of corps urbanization based on internal and external source
}

\section{dynamics}

\author{
Baolong Tian, Hongmei Chen, Yangyang Di
}

Tarim University, College of Economics and Management, Xinjiang Alar, 843300

Keywords: Corps; urbanization; internal and external sources

\begin{abstract}
Corps of economic society, how to realize urbanization and solve the problems in the development of urbanization, affect the city garrison Corps Tun and the mission of the task. This paper carries on the ponder to the urbanization development of internal and external power source based on the perspective of constructing the index system and the comprehensive measurement of towns, cities and towns from the comprehensive correlation verification inside and outside source factors, finally puts forward the corresponding countermeasures according to the relevant conclusions, hoping to contribute to the development of urbanization.
\end{abstract}

\section{The definition of internal and external sources of Urbanization}

Endogenous power is the spontaneous attraction in the social progress of the Corps, which can form the economic urbanization, population urbanization and social urbanization from the surrounding areas. Economic development is an important indicator to measure the collective progress of the region, and also plays an important role in the process of urbanization. Scholars both at home and abroad have always attached importance to the promotion of industrial transformation to the process of urbanization, and attributed it to the internal driving force for the progress of urbanization. With the Xinjiang forum and a new round of targeted aid to policy support, the development of corps entered a phase of rapid development, the social economy has been greatly improved, the economic indicators improved significantly, the industrial output value increased three times, the changes of industrial structure is reasonable, the process of industrialization promoting urbanization.

External force is the external driving force of the social advance of the Corps, and forms the population urbanization and social urbanization in the form of the thrust. Taking into account the national or regional policy, the role of government is more difficult to quantify the impact of the selection of a reference role in the construction of public services as exogenous power. Public service includes not only the infrastructure, including education, science and technology, environment, sports and social culture and other related businesses, the city infrastructure is the material carrier of the city, has an important role to maintain the city economic and social activities, including roads, railways, airports, communication, public places and other public facilities.

At present, the Corps has formed a comprehensive scientific research, education, health, sports, culture, finance, insurance and other public services. As of 2015, the Corps of 176 farms, more than 4 thousand and 700 industrial, construction, transportation, commercial enterprises, the total population of about 2700000 people. Area of more than 70 thousand square kilometers. Various types of schools 563, ordinary and adult colleges and universities, secondary vocational schools, 
such as the 24 , the average high school, the primary school, the school of 55 , the national students in the school of 481 thousand and 300 people in the 7. The corps construction of public service system to further expand the scale, has a professional culture art group 8, hundreds of amateur art groups, radio and television broadcasting agencies 197, site 66, radio and television coverage rate reached 97\% and 98.8\% respectively; tourism tourism enterprises 294, 57 star restaurants; all 1348 health institutions, health technical staff of 24 thousand and 800 people.

\section{Corps urbanization model and analysis}

Along with the urbanization process accelerated, the Division has been built at the center of construction of the city nine, and 4 divisions to be built and has been put on the agenda, the main body of urbanization includes not only the establishment of city and township, symbolic can directly reflect the status of development of urbanization index to describe the urbanization level by use of single index method, such as population urbanization, land urbanization index can not reflect the actual development of the Corps. So this paper chooses to use the composite index method which can represent the development of urbanization.

Based on the relevant research, combined with the actual development of the Construction Corps, population, society, economy three index layer and select the corresponding sub index, to study the level of corps towns from the horizontal angle, specific indicators are shown in table 1. Population urbanization indicators include $\mathrm{X} 1, \mathrm{X} 2, \mathrm{X}$ 3, economic Urbanization indicators include $\mathrm{Y} 1, \mathrm{Y} 2, \mathrm{Y} 3$, Y4, Y5, Y6, Y7, Y8, social urbanization indicators include Z1, Z2, Z3, Z4, Z5, Z6, Z7. The X1, Z3 and $\mathrm{Z7}$ of each index layer are reverse indicators, and the other indicators are positive indicators.

Table 1 index building table

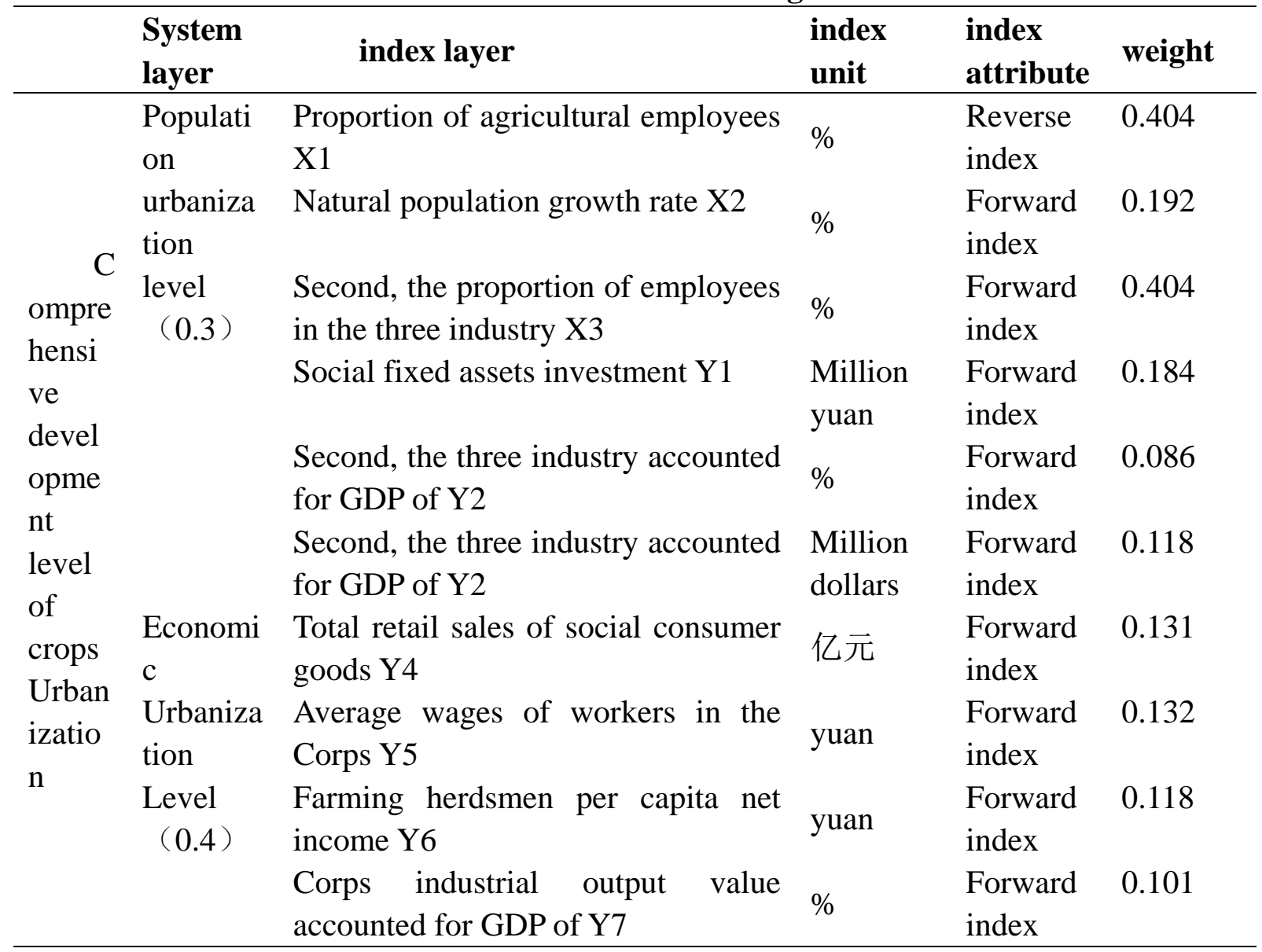




\begin{tabular}{|c|c|c|c|c|}
\hline \multirow{8}{*}{$\begin{array}{l}\text { Social } \\
\text { urbaniza } \\
\text { tion } \\
\text { level } \\
(0.3)\end{array}$} & $\begin{array}{l}\text { Per capita disposable income of } \\
\text { urban residents Y8 }\end{array}$ & yuan & $\begin{array}{l}\text { Forward } \\
\text { index }\end{array}$ & 0.106 \\
\hline & $\begin{array}{l}\text { The whole society has a number of } \\
\text { professional and technical personnel } \\
\text { Z1 }\end{array}$ & people & $\begin{array}{l}\text { Forward } \\
\text { index }\end{array}$ & 0.114 \\
\hline & $\begin{array}{l}\text { According to the type of registration } \\
\text { of goods turnover } \mathrm{Z} 2\end{array}$ & $\begin{array}{l}\text { Tons } \\
\mathrm{km}\end{array}$ & $\begin{array}{l}\text { Forward } \\
\text { index }\end{array}$ & 0.173 \\
\hline & Engel coefficient Z3 & $\%$ & $\begin{array}{l}\text { Reverse } \\
\text { index }\end{array}$ & 0.096 \\
\hline & $\begin{array}{l}\text { The number of urban population } \\
\text { insured Z4 }\end{array}$ & $\begin{array}{l}\text { ten } \\
\text { thousand } \\
\text { people }\end{array}$ & $\begin{array}{l}\text { Forward } \\
\text { index }\end{array}$ & 0.136 \\
\hline & $\begin{array}{l}\text { The number of cars per } 100 \\
\text { households in the town is Z5 }\end{array}$ & $\begin{array}{l}\text { Vehicle / } \\
\text { househol } \\
\text { d }\end{array}$ & $\begin{array}{l}\text { Forward } \\
\text { index }\end{array}$ & 0.144 \\
\hline & $\begin{array}{l}\text { Number of health technical } \\
\text { personnel Z6 }\end{array}$ & people & $\begin{array}{l}\text { Forward } \\
\text { index }\end{array}$ & 0.185 \\
\hline & $\begin{array}{l}\text { Urban registered unemployment rate } \\
\text { Z7 }\end{array}$ & $\%$ & $\begin{array}{l}\text { Reverse } \\
\text { index }\end{array}$ & 0.153 \\
\hline
\end{tabular}

Influence of urbanization comprehensive development level is mainly affected by population, economy and society three system factors, each index system of urbanization development, taking into account the impact of corps population dispersion, this paper highlights the economic effect of urbanization, urban development level evaluation in the integrated model, increase the economic weight of urbanization. The comprehensive development level of urbanization is calculated as follows:

$\mathrm{T}=\alpha \mathrm{R}+\beta \mathrm{E}+\theta \mathrm{G}$

$\mathrm{R}=\sum_{i=1}^{n} \alpha i K(X i j) \quad \mathrm{E}=\sum_{i=1}^{m} \beta i K(Y i j) \quad \mathrm{G}=\sum_{i=1}^{p} \gamma i K(Z i j)^{[2]}$

T for the comprehensive development level of urbanization, R, E, G, respectively, on behalf of population, economic and social development level of urbanization. According to the related research, the weight of alpha, beta and theta was $0.3,0.4$ and 0.3 , respectively. The higher the value, the higher the level of urbanization progress is [1]. K (Xij J) said the development level of urban population in the I index after dimensionless variables; $\mathrm{K}$ (Yij) said the Economic Urbanization in the year $\mathrm{j}$ the I index after dimensionless variables; $\mathrm{K}$ (Zij) said the society urbanization in the year $\mathrm{J}$ I index after the dimensionless variables; the weight of population, economy, society said urbanization respectively (and 1), each index weight calculation system using variation coefficient method, the various data standardization processing, calculate the standard data of the mean value, standard deviation and standard deviation coefficient, respectively. The population, society, economy urbanization index system of the standard deviation coefficient was normalized, the weight of the three index system.

First of all, the extreme value of each index data is calculated, and the data are located in (0 1), and then combined with the formula to calculate the population urbanization, economic urbanization, social urbanization evaluation results. And calculate the comprehensive development 
level.

Table 2 results of comprehensive urbanization

\begin{tabular}{lllll}
\hline Year & $\begin{array}{l}\text { Population } \\
\text { Urbanization }\end{array}$ & $\begin{array}{l}\text { Economic } \\
\text { Urbanizati } \\
\text { on }\end{array}$ & $\begin{array}{l}\text { social } \\
\text { urbanization }\end{array}$ & $\begin{array}{l}\text { comprehensive } \\
\text { urbanization }\end{array}$ \\
\hline 2005 & 0.15 & 0.03 & 0.02 & 0.063 \\
2006 & 0.09 & 0.06 & 0.06 & 0.069 \\
2007 & 0.10 & 0.20 & 0.09 & 0.137 \\
2008 & 0.12 & 0.30 & 0.16 & 0.204 \\
2009 & 0.10 & 0.34 & 0.18 & 0.220 \\
2010 & 0.19 & 0.38 & 0.12 & 0.245 \\
2011 & 0.05 & 0.52 & 0.44 & 0.355 \\
2012 & 0.06 & 0.77 & 0.65 & 0.521 \\
2013 & 0.07 & 0.90 & 0.78 & 0.615 \\
2014 & 0.06 & 0.91 & 0.82 & 0.751 \\
\hline
\end{tabular}

\section{The influence of internal and external sources of power on the urbanization of Corps}

2014 GDP reached 173 billion 868 million yuan, an increase of 16.1\% over the previous year, the per capita GDP of $\$ 63989$, an increase of $14.3 \%$ over the previous year. In all of its growth, the added value of the first industry was 41 billion 696 million yuan, the added value of the second industry was $\$ 77$ billion 686 million, the added value of the third industry was $\$ 54$ billion 486 million, the proportion of the three industry accounted for $24: 45: 31$. Three contributions to the social economy of the industry was $12.9 \%$, respectively, $61.7 \%$ and $25.4 \%$, respectively, stimulating economic growth of 2.1, 9.9 and 4.1 percentage points. Considering the industrial output value in the background of rapid development of China's social economy is a positive development, it is difficult to reflect the main force of endogenous power of industrial transformation, this paper applied the SPSS software to the three industry output value and proportion were associated with urbanization rate test. [3]

The test results show that there is a significant positive correlation between the three industries and urbanization development, the correlation coefficient is $0.980,0.991$ and 0.987 , respectively, of which the largest contribution to the second industry. The proportion of three industries and the urbanization rate have significant correlation, the correlation coefficient were $-0.931,0.962$ and -0.872, plays an important role in the development of one and two industries to urbanization, difference is that with the first industry to promote the urbanization rate have significant adverse effects, two of the industry is positive effect. Based on the above two kinds of correlation results differences can be found in the three industry and urbanization with the development of society and economy increased year by year, there is a strong positive correlation; and we identify second, the process of industrial transformation is the main impetus of urbanization endogenous development, accelerate the development of crops industrialization is the key factor to promote the town the process of.

In the whole process of urbanization, the construction of public service plays an important role in the development of urbanization. Public service includes not only the infrastructure, including education, science and technology, environment, sports and social and cultural cause, the difficulty in obtaining data into account, choose the representative at the end of the highway mileage as the 
infrastructure index, the number of graduates in various schools on behalf of education indicators, the number of employees on behalf of the science and technology index, the number of medical institutions health index.

There was a weak correlation between the exogenous dynamic index and urbanization development, and the correlation coefficients were $0.468,0.637,0.193$, and 0.308 , respectively. Visible, infrastructure, science and technology, health care and education have played a role in the development of urbanization, the number of medical institutions and urbanization is the largest correlation of 0.637 , medical progress has a greater role in urbanization.

\section{Conclusions}

The overall urbanization level of the Corps has been accelerated, economic Urbanization and social urbanization have become the main direction. Urbanization is the development of Xinjiang Construction Corps, corps construction important link, 2005-2014 years, the development speed of urbanization from the relatively slow stage to the stage of rapid development, ten years of comprehensive urbanization level increased from 0.063 to 0.751 , has been significantly improved, and the process of urbanization from the population urbanization development situation has been changed into economy urbanization and social urbanization development, overall realize people-oriented new urbanization development ideas.

To encourage the system innovation. Has a guiding role in the development of corps system innovation of urbanization, the system has a long history, has the characteristics of Xinjiang, is a major guarantee for the Corps adhere to the historical mission of the city and the village. In the context of the development of the times, the Corps is facing more arduous task, so in the work, system, thinking, we need to follow the pace of the times, the construction of new Corps, the development of the corps to clear the institutional obstacles. Clear under the new situation in the Corps of the nature, position and role, responsibilities and obligations, to explore the relationship of corps system and market economy, achieve mutual benefit and common development, and gives suggestions for further administrative Corps financial and tax privileges on the actual situation is conducive to make policy decisions and different development policy.

\section{Acknowledgment}

Found Project: Social Science Fund Project "Youth Corps Corps urbanization dynamic mechanism research" (project number: 14QN16); President of Tarim University Social Science Fund Project "Research on alar city water resources security under the new urbanization background based on" (project number: TDSKSS1403); "the research and development of new towns in the process of Service Corps cooperation" (project number: TDSKSS1503).

\section{References}

[1] Zhan C G, Pan W H, Qing J I. Dynamic Monitoring and Spatial-Temporal Analysis of Urban Heat Island based on Modis Data[J]. Journal Of Tropical Meteorology, 2011, 27(3):396-402.

[2] Lan J, Yu D, Ran B, et al. A new threat degree analysis method of abandoned objects based on dynamic multifeature fusion in urban traffic[J]. Journal of Intelligent Transportation Systems, 2016, 34(2):1-12. 
[3] Xu M, Gao Z. Chaos in a dynamic model of urban transportation network flow based on user equilibrium states[J]. Chaos Solitons \& Fractals, 2009, 39(2):586-598.

[4] Surbeck C Q. Dynamics of Point and Non-Point Source Fecal Pollution from an Urban Watershed in Southern California[J]. Lancet, 2005, 372(9656):2115 - 2123.

Author: Tian Baolong (1986-), male, master, lecturer, research direction: regional economy; Chen Hongmei (1986-), female, master, lecturer, research direction: the development and utilization of water resources; Di Yang Yang (1987-), female, master, lecturer, research direction: regional economic and financial accounting. 